\title{
Sistem Basis Data Manajemen Akademik dengan Platform Web pada Sekolah Menengah Atas Muhammadiyah 4 Bandung
}

\author{
Ayu Hidayah Aslamia ${ }^{1}$, Herru Darmadi² \\ Computer Science Department, School of Computer Science, \\ Bina Nusantara University, \\ Jakarta, Indonesia 11480 \\ aaslamia@binus.edu; hdarmadi@binus.edu
}

\begin{abstract}
The purpose of this research is to design a database system that is implemented in a web-based academic management that can be used to support the information system and academic management at Muhammadiyah 4 High School Bandung. The proposed Method in system design includes 2 parts, such as system analysis and product design. Analytical methods include literature studies, interviews, and questionnaire. Meanwhile, the database design method used are three stages database design according to Connoly and Begg. The results achieved are web based academic and database management system at Muhammadiyah High School 4 Bandung. The conclusion obtained from this research is the system is able to provide information needs, faster, accurate, prevent duplication problem of data, to support decision making, to improve effective communication between the user, and to get the information easier.
\end{abstract}

Keywords: Web-Based; Senior High School; Academic Management System

\footnotetext{
Abstrak - Tujuan daripenelitian ini adalah untukmendesain system basis data yang diimplementasikan pada sebuah basis web manajemen akademik yang akan dimanfaatkan untuk mendukung sistem informasi dan manajemen akademik di Sekolah Menengah Atas Muhammadiah 4 Bandung. Metode yang digunakan dalam mendesain system terdiri dari dua bagian, yaitu analisis system dan desain produk. Metode analitikal meliputi studi literatur, interview, dan kuesioner. Sementara, desain basis data yang digunakan terdiri dari tiga tahapan desain basis data yang dikemukakan oleh Connoly dan Begg. Hasil yang dicapai adalah Akademik berbasis web dan basis data system manajemen di Sekolah Menengah Atas Muhammadiyah 4 Bandung. Kesimpukan yang didapat dari penelitian ini berupa sebuah system yang mampu mendukung kebutuhan informasi agar lebih cepat, akurat, mencegah terjadinya duplikasi data, mendukung pengambilan keputusan,
}

meningkatkan efektivitas komunikasi antar pengguna dan untuk memperoleh informasi lebih mudah.

Keywords: Basis-WEB; Sekolah Menengah Atas; Sistem Manajemen Akademik

\section{PENDAHULUAN}

Di era Globalisasi ini, teknologi dan informasi berkembang begitu pesat. Sehingga persaingan untuk mengembangkan teknologi di bidang informasi sangat bermanfaat untuk menghasilkan pekerjaan yang efisiensi. Salah satu teknologi yang semakin tumbuh dengan cepat dalam jangka waktu yang cukup singkat yaitu computer (Conolly \& Begg, 2015).

Perkembangan aplikasi perangkat lunak digunakan untuk mendukung pemanfaatkan sistem informasi. Penerapan teknologi informasi dan aktifitas dalam penggunaannya dalam mendukung kegiatan operasional manajemen akademik merupakan gabungan dari sistem informasi.

Dalam bidang akademik dan operasionalnya sehari-hari, teknologi informasi semakin efisien jika ditunjang dengan internet, di mana internet merupakan alat komunikasi yang cukup terjangkau dalam transaksi antara dua atau lebih pengguna. Sehingga kemapuan karakteristik dari teknologi internet dapat mendukung terjadinya proses belajar mengajar jarak jauh yang lebih efektif serta efisien.

Perkembangan aplikasi perangkat lunak digunakan untuk mendukung pemanfaatkan sistem informasi. Penerapan teknologi informasi dan aktifitas dalam penggunaannya dalam mendukung kegiatan operasional manajemen akademik merupakan gabungan dari sistem informasi.

Dalam bidang akademik dan operasionalnya 
sehari-hari, teknologi informasi semakin efisien jika ditunjang dengan internet, di mana internet merupakan alat komunikasi yang cukup terjangkau dalam transaksi antara dua atau lebih pengguna. Sehingga kemapuan karakteristik dari teknologi internet dapat mendukung terjadinya proses belajar mengajar jarak jauh yang lebih efektif serta efisien.

Sistem Informasi diharapkan dapat dimanfaatkan dan digunakan secara bersama dalam waktu yang bersamaan. Sehingga perlu diterapkan jaringan komputer untuk mengkoneksikan antar sistem informasi.

Menurut Setiawan dan Purnama, (2013), Jaringan komputer merupakan perkembangan teknologi yang memanfaatkan beberapa perangkat komputer untuk dapat berbagi dan menerima informasi. Pengguna yang menerima maupun meminta informasi ataupun data disebut client. Sedangkan pengguna yang memberikan atau mengirimkan informasi disebut server. Sehingga proses transaksi atau desain ini disebut juga dengan sistem client-server yang dimanfaatkan untuk menunjang sistem pelayanan informasi akademik seperti yang sedang dikembangkan di SMA Muhammadiyah 4.

Dalam kegiatan transaksi manajemen akademik, SMA Muhammadiyah 4 masih dilakukan secara manual tanpa terkomputasi maupun terintegrasi. Sehingga belum secara maksimal menghasilkan data dan informasi secara konsisten dan maksimal. Saat ini, Sma Muhammadiyah 4 bermaksud mengembangkan kurikulum akademik berbasis IT untuk menunjang manajemen sekolah berbasis web, yaitu BEST Education System yang menjadi salah satu target kurikulum SMA Muhammadiyah 4.

SMA Muhammadiyah berharap BEST Education System dapat dijadikan sarana bagi sekolah dalam membangun komunikasi antara pihak sekolah dengan wali siswa dalam proses operasional akademik. Seperti contoh, wali siswa dapat menerima informasi berupa laporan absensi siswa, nilai ujian, jadwal pelajaran, biaya pendidikan baik tagihan SPP maupun tunggakan dan informasi lainnya yang dapat diakses oleh masing-masing wali siswa melalui website.

BEST Education System diharapkan mampu menjadi sarana bagi para siswa dalam berdiskusi maupun menjawab kuis dari guru secara online, memperoleh kuis latihan maupun tugas yang dapat diupload oleh guru melalui forum. Dengan ini, siswa akan lebih mudah menerima dan mengerjakan tugas dari guru tanpa harus bertatapan langsung dengan guru yang bersangkutan, selama setiap pengguna memiliki akses internet. Selain itu, sistem juga dilengkapi fitur yang dapat memudahkan proses komunikasi yang interaktif seperti fitur pada jejaring sosial, karena BEST Education System menyediakan forum diskusi agar antar siswa maupun guru dan siswa dapat berkomunikasi sesuai topik diskusi yang ditentukan oleh pembuat thread.

Dari sisi SMA Muhammadiyah 4, BEST Education System diharapkan dapat menjadi sarana penyimpanan data sekolah baik master data siswa, data keuangan siswa, data kepegawaian dan dapat dimanfaatkan untuk memudahkan proses operasional manajemen bagi para staff pendidikan seperti staff Tata Usaha. Sehingga BEST Edcuation System mampu meningkatkan mutu dan pelayanan akademik pada SMA Muhammadiyah 4 Bandung (U. Rosidin, 2013).

Saat ini sekolah sudah pernah melakukan penelitian berupa manajemen akademis sekolah dan lembaga bimbingan belajar yang menghasilan jurnal. Hasil luaran dari penelitian tersebut telah mampu mengubah manajemen akademis manual (pembukuan) menjadi lebih efisien dan terkomputasi melalui integrasi dan transasi data berbasis web.

Metode yang digunakan pada penelitian ini adalah: (1) Metode analisis dengan melakukan pengumpulan data dari hasil wawancara dan kuesioner. Dalam tahap analisa data, penulis melakukan wawancara terhadap Kepala Sekolah bidang kesiswaan SMA Muhammadiyah 4 untuk memproleh informasi sistem yang sedang berjalan. Setelah itu penulis menyebarkan kuesioner kepada beberapa siswa yang dipilih sebagai responden untuk memperoleh menganalisa sistem yang sedang dibutuhkan SMA Muhammadiyah 4 (2). Membuat rancangan database menggunakan pustaka "Database System" karangan Connolly dan Begg (2015). Rancangan basis data tersebut terdiri dari 3 tahapan, yaitu: Conteptual Database Design, Logical Database Design dan Physical Database Design. (3) Selanjutnya pengembangan sistem menggunakan metode Waterfall menurut pressman (2015). Untuk menerapkan metode ini, penulis menggunakan beberapa langkay, yaitu: (a). Communication: Berkomunikasi langsung dengan pengguna dan stakeholder untuk membahas tujuan dari pembangunan sistem. Proses ini sangat penting dilakukan agar setiap pengguna sistem memahami dengan baik tujuan dan manfaaat dari sistem yang akan dibangun. Selain itu juga bertujuan untuk mengumpulkan data yang dibutuhkan pada proses analisa data. (b) Planning: mendesain Software Project Plan dengan mengarahkan tim dalam mengerjakan proyek. Pada tahapan ini, penulis menjelaskan tugas dari software engineer dengan menjelaskan proses teknikal yang harus dilakukan, sumber daya (resource) yang dibutuhkan, output yang akan dihasilkan dan taskline proses pengerjaan proyek.

(c) Modelling: Untuk memenuhi kebutuhan software, penulis merancang model agar kebutuhan dapat dipahami dengan lebih baik. (d) Construction: Menjalankan tahapan testing atau percobaan terhadap code yang dihasilkan. Hal ini bertujuan untuk memperbaiki error apabila terdapat bug pada program. (e) Deployment: Program yang sudah diselesaikan dan sudah melalui tahapan uji percobaan (testing) diserahkan kepada pihak SMA Muhammadiyah 4 untuk dievaluasi. Dalam tahapan ini, sistem yang sudah dibuat dicoba oleh user untuk memperoleh feedback berdasarkan evaluasi.

\section{METODOLOGI PENELITIAN}

Dalam menjalankan penelitian ini, terdapat tiga metode yang penulis gunakan, yaitu: (1) Mengidentifikasi tipe entitas, (2) Problem Analisis, (3) Analisis Aplikasi Sejenis, (4) Analisis Sistem yang Berjalan, (5) Analisis Kebutuhan User, (6) Identifikasi Masalah, (7) Hasil 
Kuesioner, (8)Deployment.

\subsection{Communication}

Pada tahap Communication, penulis melakukan survei ke SMA Muhammadiyah 4 Bandung, dengan mewawancarai Wakil Kepala Sekolah SMA Muhammadiyah 4 Bandung yang bernama Bapak Firdaus Sholeh. Menurut Bapak Firdaus, Sistem yang dibutuhkan oleh SMA Muhammadiyah 4 adalah sistem yang dapat mendukung kegiatan pembelajara, seperti melihat nilai, mengecek absensi, sistem keuangan, forum diskusi sebagai sarana antara siswa dan guru untuk melakukan sharing materi dan tugas secara online. Sistem juga membutuhkan fitur messaging yang emungkinkan siswa dan guru dapat berkomunikasi secara private.

Penulis juga membagikan kuisioner kepada beberapa sample siswa dan guru yang bertujuan untuk memperoleh informasi mengenai sistem yang dibutuhkan oleh user dan mengetahui seberapa penting sistem yang dibutuhkan.

\subsection{Problem Analysis}

Penulis melakukan analisis masalah untuk membantu mengarahkan tim mengerjakan proyek. Berupa desain aplikasi, desain basis data dan modul yang digunakan untuk mengarahkan dalam pembuatan sistem agar dapat dkerjakan secara sistematis.

\subsection{Analisis Aplikasi Sejenis}

Salah satu aplikasi sejenis yang menjadi acuan penulis dalam pembuatan aplikasi ini adalah dari Universitas Bina Nusantara melalui sarana sistem manajemen akademik yang menjadi salah satu andalan bagi pihak akademik dalam meningkatkan mutu dan kualitas peserta didiknya, yaitu Binusmaya (http://binusmaya.binus.ac.id).

\subsection{Analisis Sistem yang Berjalan}

Dari hasil wawancara yang dilakukan di Sekolah Menengah Atas Muhammadiyah 4 Bandung kepada pihak Kepala Sekolah, Wakil Kepala Sekolah, guru serta beberapa siswa, serta melakukan observasi terhadap sistem yang telah digunakan dan berjalan saat ini, penulis menyimpulkan beberapa sistem yang sedang berjalan, seperti Guru mememiliki batas absensi sesuai peraturan di sekolah, daftar kehadiran guru di sekolah dicatat dan diakumulasikan oleh seorang pegawai yang diberikan tugas khusus untuk mencatat absensi guru, Hasil akumulasi kehadiran guru di sekolah diserahkan kepada kepala sekolah. Selain itu, siswa mememiliki batas absensi sesuai peraturan di sekolah, siswa yang bertugas sebagai sekretaris kelas mencatat kehadiran siswa di sekolah, setiap bulan daftar hadir siswa diberikan kepada wali kelas, wali kelas mengakumulasi data daftar hadir untuk menentukan kedisiplinan dan pengisian di raport, hasil akumulasi kehadiran siswa di sekolah diserahkan kepada kepala sekolah. Permasalahan yang ada pada sistem adalah terjadi delay ketika akan mengagregasi informasi dikarenakan proses pendataan manual seperti penghitungan dan pencarian berkas daftar hadir siswa, serta diserahkan kepada kepala sekolah pada setiap bulan. Interaksi antara siswa dan guru harus dilakukan secara tatap muka sesuai jadwal yang ditentukan sehingga menyulitkan guru untuk meluangkan waktu bagi siswanya melakukan proses belajar mengajar ketika tidak berada di kelas. Selain itu, sulitnya menjangkau data yang dibutuhkan. Para staff guru, siswa maupun alumni harus menemui bagian tata usaha untuk memperoleh data, kelemahannya yaitu proses pencarian data secara manual memakan waktu yang lebih lama selain itu keamanan data kurang terjamin. para siswa harus menunggu jadwal pelajaran secara berkala melalui wali kelas masing-masing. Daftar jadwal pelajaran disimpan oleh siswa secara manual sehingga ketika jadwal pelajaran hilang atau siswa lupa dengan jadwal pada hari tertentu, siswa harus bertanya kepada teman sekelasnya. Terdapat beberapa masalah seperti adanya data pembayaran yang hilang bahkan rusak yang terjadi sebelum agregasi data pada laporan pembayaran. Hal ini mengakibatkan inkonsistensi pada data. Selain itu pengguna memerlukan waktu lama untuk mendapatkan informasi yang diperlukan karena para guru memberikan daftar nilai pada waktu yang berbeda secara manual pada wali kelas, sehingga agregasi informasi hanya dapat dilakukan setelah seluruhnya terkumpul lengkap dan barulah dapat dibuat sebagai laporan rapor siswa.

Selanjutnya, wali kelas harus mencari siswa dan memberitahukan secara langsung, atau dengan melakukan panggilan kepada siswa untuk menemui guru di ruang guru sehingga menyulitkan proses penyampaian informasi kepada siswa, serta wali murid akan membutuhkan waktu yang lama dan kinerja yang lebih banyak. Penyampaian informasi kepada wali murid secara langsung sering menimbulkan kekeliruan.

\subsection{Analisis Kebutuhan User}

Pada Analisis kebutuhan user, pengguna membutuhkan fitur berupa Nilai ujian terdiri dari tiga tipe, yaitu Ulangan Harian (UH), Ujian Tengah Semester (UTS) dan Ujian Akhir Semester (UAS), dimana hasil nilai ujian diproleh dari masing-masing guru mata pelajaran kemudian diserahkan kepada wali kelas untuk direkap, kemudian diserahkan ke admin untuk diinput ke dalam sistem untuk ditampilkan. Profil siswa digunakan untuk menampilkan data pribadi siswa seperti foto profil dan biodata diri ketika user berhasill login.

Sekolah memiliki arsip berupa data pribadi siswa yang kemudian diinput oleh admin untuk dapat diakses sebagai profil siswa. Profil guru digunakan untuk menampilkan data pribadi guru seperti foto profil dan biodata diri ketika user berhasill login.

Sekolah memiliki arsip berupa data pribadi guru yang kemudian diinput oleh admin untuk dapat diakses sebagai profil guru, Finance siswa terdiri dari biaya SPP, BP3 dan beberapa kolom tertentu sebagai tagihan tambahan. Dalam hal ini, user menginginkan fitur finance siswa bersifat fleksibel untuk menempatkan beberapa tagihan tambahan selain SPP dan BP3. Dalam prosedur ini, siswa melakukan transaksi pembayaran melalui bagian Tata Usaha (TU) kemudian data jatuh tempo yang sudah lunas ataupun belum lunas akan dialihkan ke admin untuk diinput dan ditampilkan di sistem. Daftar kehadiran siswa diperoleh dari hasil absensi setiap hari yang dilakukan oleh sekretaris kelas. Kemudian daftar absensi diserahkan kepada admin untuk diinput ke dalam sistem database. 
Masing-masing kelas memiliki wadah untuk mendiskusikan maupun sharing mengenai materi pelajaran. Dan forum dapat diakses oleh masing-masing kelas dengan guru mata pelajaran yang bertugas. Setiap user memiliki wadah untuk dapat melakukan private communication secara online. Dengan fitur ini, guru dapat berinteraksi secara langsung dengan siswa secara pribadi begitu juga dengan wali siswa. Serta masing-masing kelas memiliki jadwal mata pelajaran. Hasil rapat anggota guru dalam membahas masing-masing jadwal mata pelajaran kelas, daftar tersebut diserahkan kepada amin untuk diinput dan ditampilkan untuk dapat diakses oleh masing-masing siswa sesuai dengan jadwal kelasnya.

\subsection{Identifikasi Masalah}

Instrumen yang digunakan untuk melakukan identifikasi masalah adalah dengan melakukan wawancara dengan Wakil Kepala Sekolah SMA Muhammadiyah 4 bagian Kurikulum, yaitu Bapak Firdaus Sholeh, S.Si pada hari Sabtu tanggal 5 Oktober 2013 pukul 10.00 WIB di ruang guru. Pihak SMA Muhammadiyah 4 menyadari bahwa penggunaan sistem online saat ini sudah banyak diterapkan dan merupakan sarana yang dapat membantu proses peningkatan mutu pendidikan di SMA Muhammadiyah 4, maka pihak sekolah membutuhkan sistem tersebut untuk mendukung operasional dan memajukan kualitas pendidikan di SMA Muhammadiyah 4.

\subsection{Hasil Kuesioner}

Penyebaran kuisioner kepada guru bertujuan untuk mengetahui presentase kebutuhan penggunaan sistem basis data akademik dengan platform web pada Sekolah Menengah Atas Muhammadiyah 4 Bandung dan sistem yang diperlukan.

Data yang terkumpul digunakan untuk melakukan analisis terhadap kebutuhan sistem. Jumlah responden pada kuesioner adalah 15 guru dan 25 siswa.

merasa kesulitan $\quad$ tidak merasa kesulitan

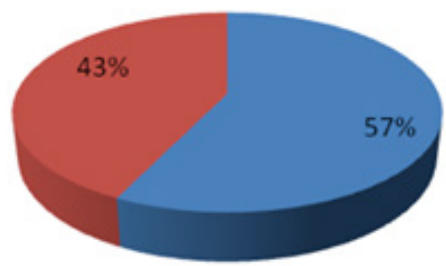

Gambar 2. Kuesioner Guru Persentase Kesulitan Input Data

Dari 14 guru, 8 diantaranya merasa kesulitan dalam menginput nilai siswa secara manual. Oleh karena itu dibutuhkan sistem menginput nilai baru yang lebih mudah

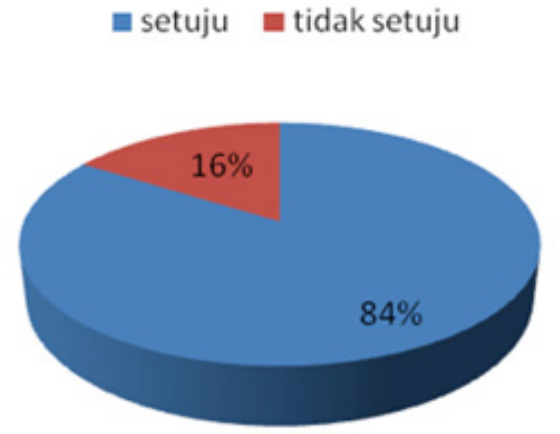

Gambar 3. Kuesioner Siswa Persentase Kebutuhan Akses Keuangan secara Online

Dari 25 siswa, 21 siswa menyatakan setuju apabila sekolah menyediakan sistem online untuk mengecek jumlah absensi siswa. Oleh karena itu sistem absensi online perlu diterapkan.

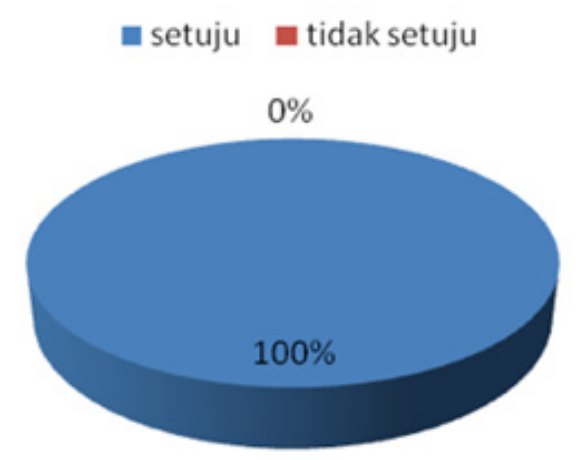

Gambar 4. Kuesioner Guru Persentase Penggunaan Messaging

Dari 14 guru, seluruhnya menyatakan setuju jika sekolah menyediakan fitur private messaging bagi guru. Maka penerapan sistem messaging perlu dijalankan.

\subsection{Deployment}

Untuk penjelasan sistem yang sedang berjalan saat ini, penulis telah merancang rich picture untuk masingmasing actor yang $\mathrm{m}$ dalam melakukan transaksi: 


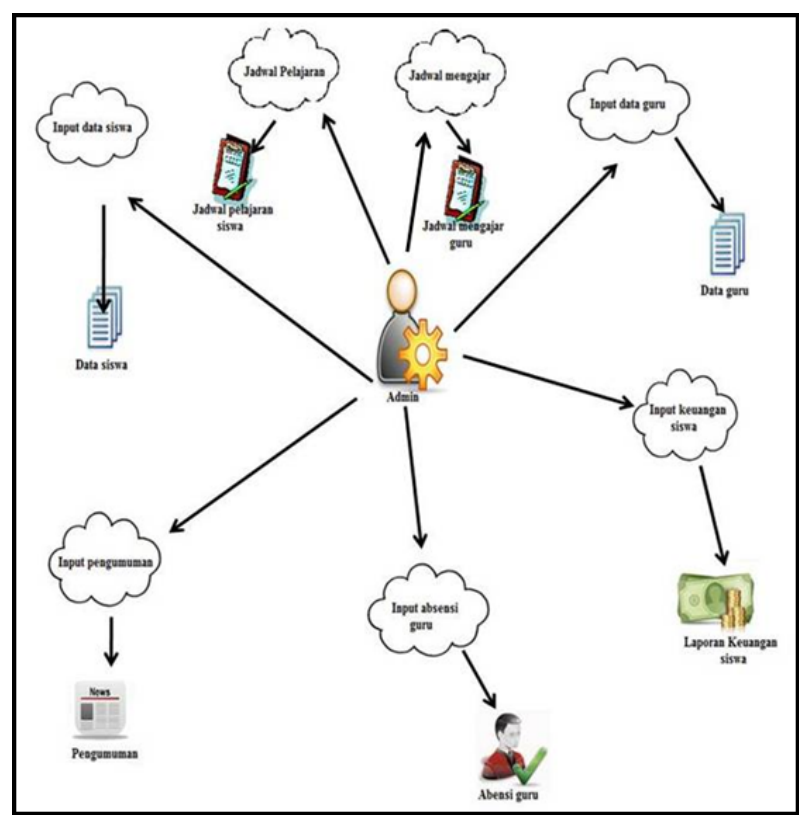

Gambar 5. Rich Picture Sistem Basis Data untuk Admin

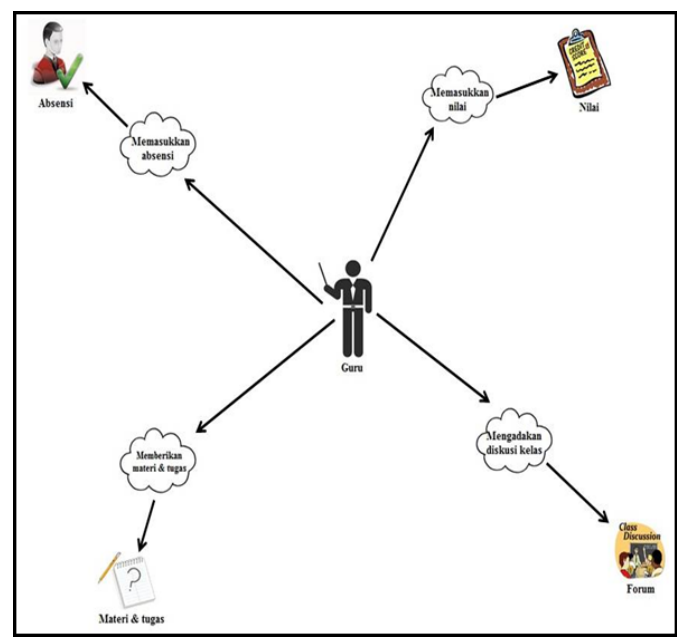

Gambar 6. Rich Picture Sistem Basis Data untuk Guru

Dalam pembuatan sistem basis data akademik dengan platform web pada Sekolah Menengah Atas Muhammadiyah 4 Bandung. Pada Tabel 1 menjelaskan mengenai entitas yang dibutuhkan:

Tabel 1. Mengidentifikasi Tipe Entitas

\begin{tabular}{|c|c|c|}
\hline Entity Name & Description & Occurence \\
\hline Subject & $\begin{array}{l}\text { Mata pelajaran } \\
\text { yang diajarkan } \\
\text { pada SMA } \\
\text { Muhammadiyah } \\
4 \text { Bandung }\end{array}$ & $\begin{array}{l}\text { Satu subject } \\
\text { memiliki beberapa } \\
\text { score, dan beberapa } \\
\text { detail_schedule }\end{array}$ \\
\hline Forum_subject & $\begin{array}{l}\text { Daftar topik } \\
\text { subject di forum }\end{array}$ & $\begin{array}{l}\text { Satu forum_subject } \\
\text { memiliki beberapa } \\
\text { thread, satu Forum } \\
\text { subject memiliki } \\
\text { satu subject }\end{array}$ \\
\hline Parents & $\begin{array}{l}\text { Orangtua atau } \\
\text { wali siswa }\end{array}$ & $\begin{array}{l}\text { Satu parents } \\
\text { memiliki beberapa } \\
\text { student }\end{array}$ \\
\hline
\end{tabular}

\begin{tabular}{cll}
\hline User & $\begin{array}{l}\text { Pengguna } \\
\text { aplikasi web }\end{array}$ & $\begin{array}{l}\text { Satu } \text { user memiliki } \\
\text { beberapa message, } \\
\text { dan kehadiran }\end{array}$ \\
\hline Test & Ujian & $\begin{array}{l}\text { Satu } \text { test } \text { memiliki } \\
\text { score } \text { dan beberapa } \\
\text { test_type }\end{array}$ \\
\hline Test_type & Jenis ujian & $\begin{array}{l}\text { Satu test_type } \\
\text { memiliki beberapa } \\
\text { test }\end{array}$ \\
\hline Thread & Daftar subject di & $\begin{array}{l}\text { Satu } \text { thread } \\
\text { memiliki beberapa } \\
\text { forum_subject, satu } \\
\text { thread } \text { memiliki } \\
\text { banyak post }\end{array}$ \\
\hline Post & Pesan teks di & $\begin{array}{l}\text { Beberapa post } \\
\text { memiliki satu } \text { thead }\end{array}$
\end{tabular}

Tabel 2. Mengidentifikasi Tipe Entitas (Cont.)

\begin{tabular}{|c|c|c|}
\hline Entity Name & Description & Occurence \\
\hline Teacher & Pengajar siswa & $\begin{array}{l}\text { Satu teacher } \\
\text { memiliki } \\
\text { beberapa class }\end{array}$ \\
\hline Attendance & $\begin{array}{l}\text { Daftar kehadiran } \\
\text { siswa dan guru }\end{array}$ & $\begin{array}{l}\text { Satu } \\
\text { attendance } \\
\text { memiliki satu } \\
\text { status }\end{array}$ \\
\hline Status & Status kehadiran & $\begin{array}{l}\text { Satu status } \\
\text { memiliki satu } \\
\text { attendance }\end{array}$ \\
\hline Class & $\begin{array}{l}\text { Kelas yang } \\
\text { ada di SMA } \\
\text { Muhammadiyah } 4 \\
\text { Bandung }\end{array}$ & $\begin{array}{l}\text { Satu class } \\
\text { memiliki } \\
\text { beberapa } \\
\text { student, dan } \\
\text { satu program }\end{array}$ \\
\hline Shift & Batas waktu & $\begin{array}{l}\text { Satu shift } \\
\text { memiliki } \\
\text { beberapa detail } \\
\text { schedule }\end{array}$ \\
\hline Finance_type & $\begin{array}{l}\text { Jenis pembayaran } \\
\text { yang dilakukan oleh } \\
\text { siswa }\end{array}$ & $\begin{array}{l}\text { Satu finance } \\
\text { type memiliki } \\
\text { beberapa } \\
\text { finance }\end{array}$ \\
\hline Header_schedule & Jadwal kelas siswa & $\begin{array}{l}\text { Satu header } \\
\text { schedule } \\
\text { memiliki } \\
\text { satu atau } \\
\text { lebih detail__ } \\
\text { schedule, } \\
\text { satu header_ } \\
\text { schedule } \\
\text { memiliki satu } \\
\text { class }\end{array}$ \\
\hline Detail_schedule & $\begin{array}{l}\text { Berisi detail } \\
\text { schedule }\end{array}$ & $\begin{array}{l}\text { Satu detail_ } \\
\text { schedule } \\
\text { memiliki } \\
\text { satu header_- } \\
\text { schedule, satu } \\
\text { subject, satu } \\
\text { teacher, dan } \\
\text { beberapa shift }\end{array}$ \\
\hline
\end{tabular}




\begin{tabular}{clc}
\hline File & $\begin{array}{l}\text { Berisi file yang } \\
\text { disimpan }\end{array}$ & $\begin{array}{l}\text { Satu file } \\
\text { memiliki satu } \\
\text { thread }\end{array}$ \\
\hline Period & Batas tahun & - \\
\hline
\end{tabular}

\subsection{Desain Penelitian}

Tujuan dari langkah ini yaitu menentukan hubungan antara tipe-tipe entitas yang telah diidentifikasi sebelumnya, pengecekan terhadap fan trap dan chasm trap pada rancangan.

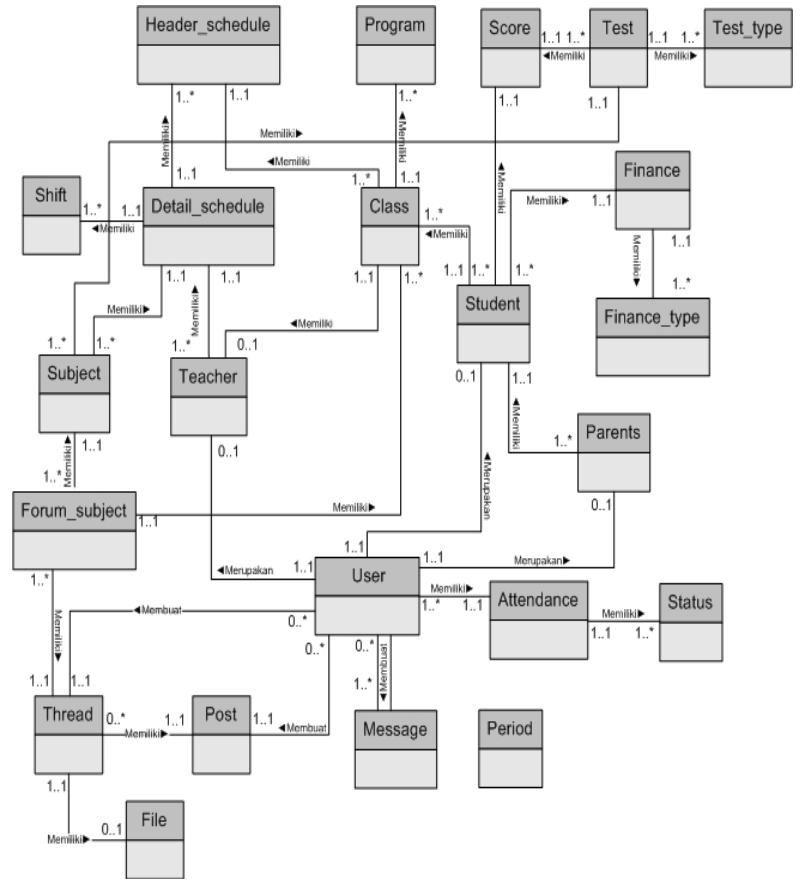

Gambar 7. Tipe Entitas Perancangan Basis Data SMA Muhammadiyah 4 Bandung

Selain itu model relasi juga digunakan untuk memastikan bahwa data yang digunakan tidak mengalami redudansi atau duplikat data.

Pada realasi teacher, student, parents, dan pengguna tidak ada redudan karena merupakan bagian dari entitas yang sama.

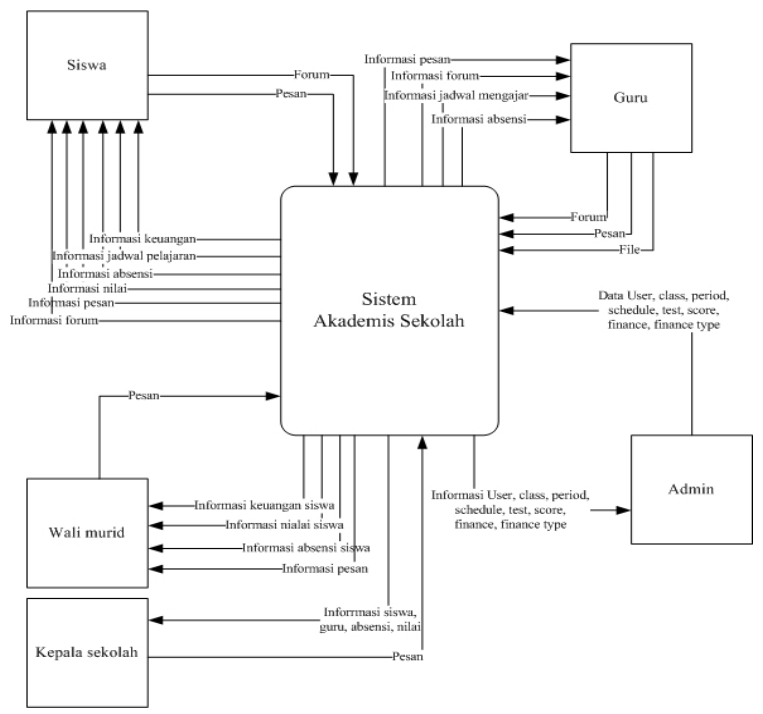

Gambar 9. Perancangan ERD untuk Data Fisikal SMA Muhammadiyah 4 Bandung
Adapun Entity Relationship Diagram yang telah dirancang oleh penulis untuk membangun hubungan antara basis data dapat dilihat pada gambar berikut:

Rancangan fisikal dari basis data bertujuan untuk memberikan penjelasan dari implementasi basis data di secondary storage (harddrive), antara lain menjelaskan relasi dasar, organisasi dokumen, dan indeks yang digunakan untuk efisiensi data akses, serta

kendala intergitas lainnya yang terkait dan langkahlangkah security.

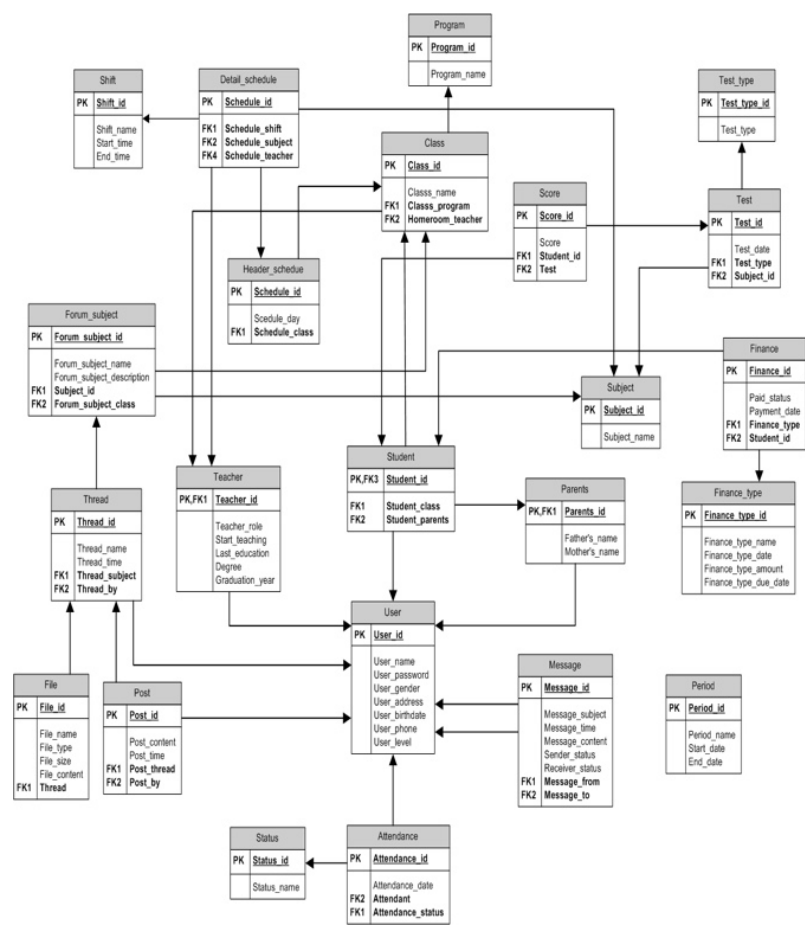

Gambar 10. Diagram Konteks untuk Data Fisikal SMA Muhammadiyah 4 Bandung

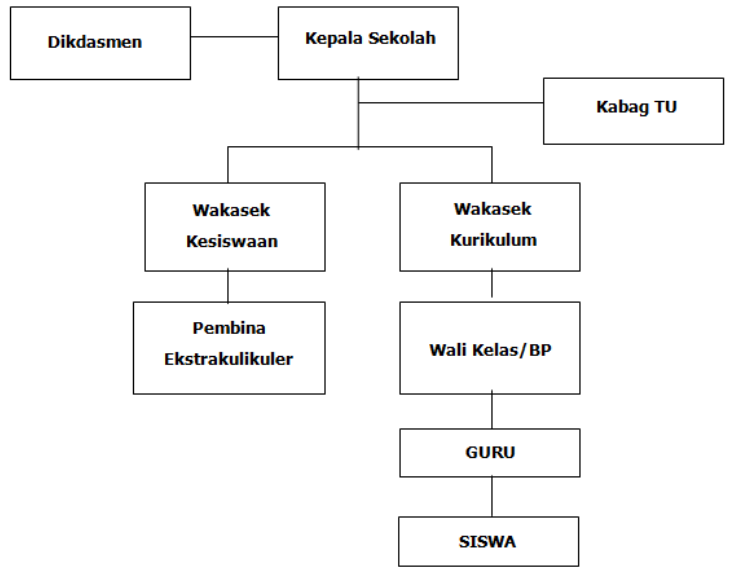

Gambar 11. Struktur Organisasi SMA Muhammadiyah 4 Bandung

Pada Struktur Organisasi Sekolah Menengah Atas Muhammadiyah 4 Bandung, Dikdasmen menyediakan fasilitas pendidikan untuk mengawasi kurikulum yang sedang berlangsung.

Berikut merupakan tampilan layar sistem basis data 
akademik dengan platform web pada Sekolah Menengah Atas Muhammadiyah 4 sesuai hak akses pengguna:

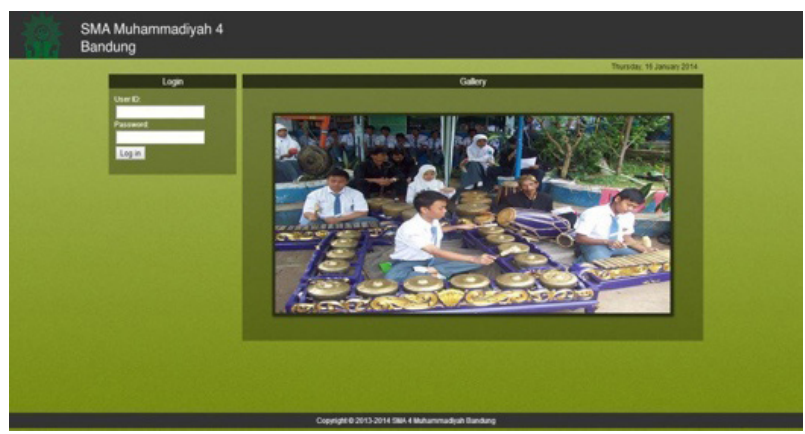

Gambar 12. Tampilan Menu Utama

Pada menu utama, seluruh pengguna diminta untuk mengisi User ID dan password yang tepat agar dapat masuk ke halaman selanjutnya.

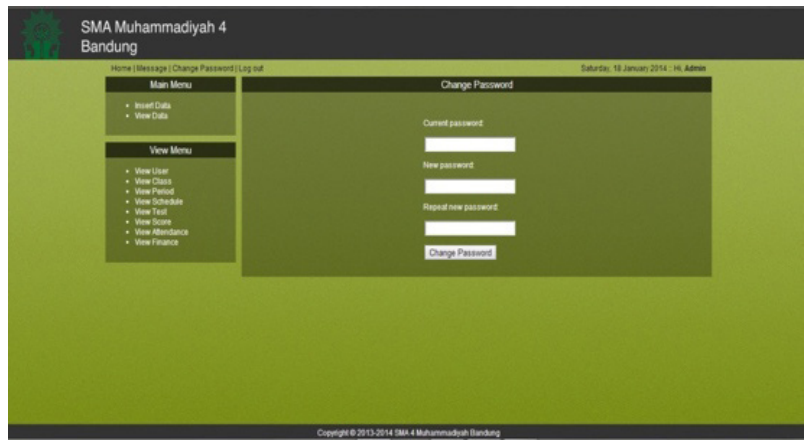

Gambar 13. Tampilan Ganti Password

Pada halaman Change Pssword, pengguna dapat mengganti password yang lama dengan password yang baru sesuai keinginan pengguna. Pada kolom Current Password, pengguna diwajibkan mengisi password yang lama dengan benar setelah itu mengisi kolom new password dan repeat password dengan password yang baru.

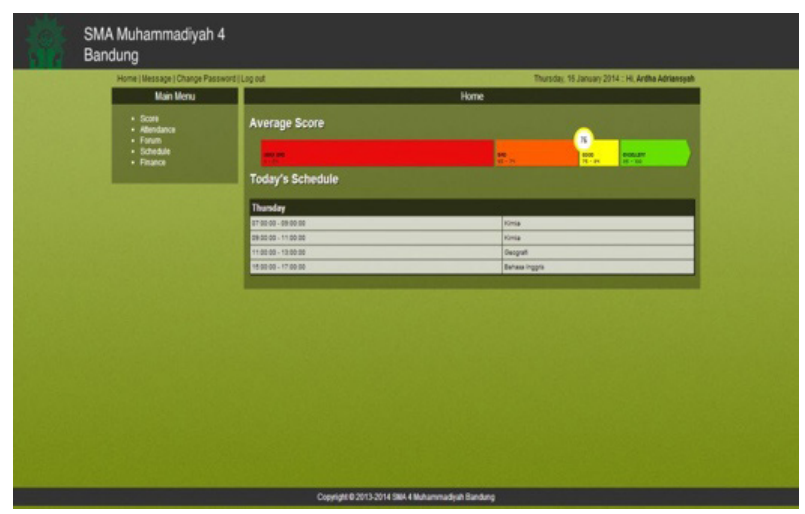

Gambar 14. Tampilan Home siswa

Setelah berhasil login, siswa akan masuk ke halaman home yang menampilkan jadwal pelajaran yang akan diterima pada hari ini. New Password dan Repeat Password harus diisi pengguna dengan password yang sama.

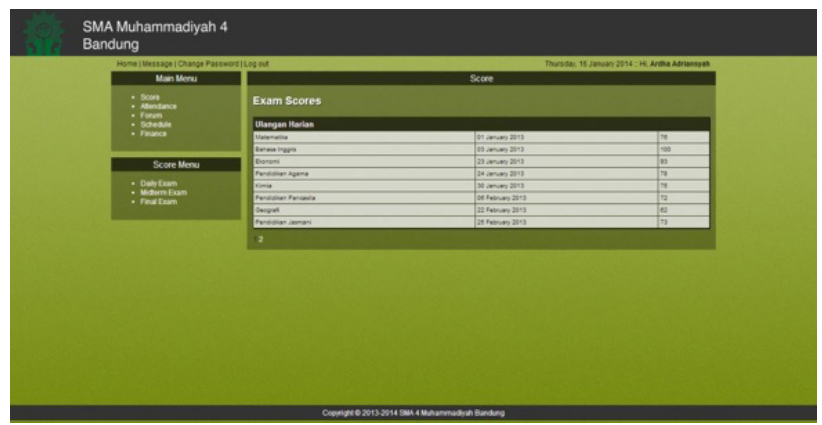

Gambar 15. Tampilan Score Siswa

Pada tampilan Score, siswa dapat melihat nilai yang diproleh, baik nilai ulangan harian, UTS maupun UAS.

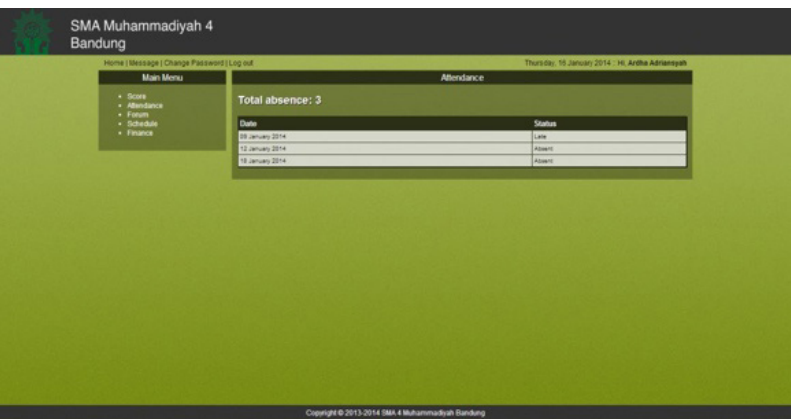

Gambar 16. Tampilan Attendance Siswa

Pada tampilan Attendance, siswa dapat melihat jumlah ketidak hadiran siswa dalam satu priode, beserta tanggal dan status ketidak hadiran siswa pada tanggal tersebut.

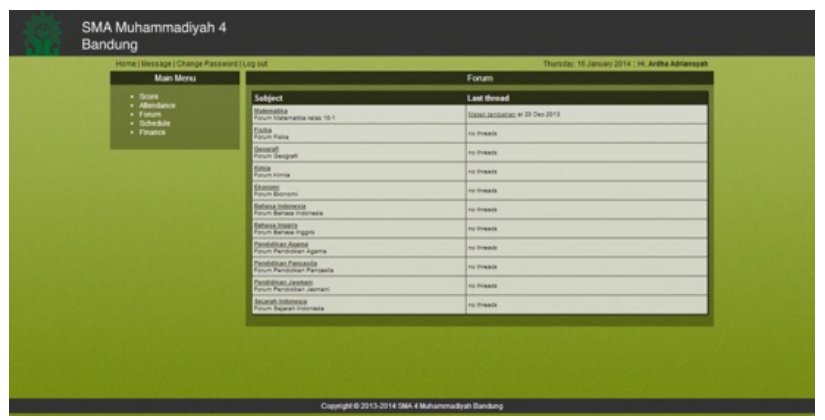

Gambar 17. Tampilan Forum

Pada tampilan Forum, siswa dapat melihat seluruh daftar bahan diskusi yang telah ter-posting sebelumnya. Pada tampilan Forum $>>$ Subject, siswa dapat melihat forum yang ditampilkan sesuai mata pelajaran. Pada tampilan Forum $>>$ Topic, siswa dapat membalas forum dan men-download materi tambahan yang diberikan guru.

\section{HASIL DAN PEMBAHASAN}

Dalam implementasi basis data, batasan domain atribut telah diimplementasikan dengan menggunakan tipe data dan batasan yang telah dibuat pada tahapan perancangan basis data, sehingga pengguna tidak dapat memasukkan data yang panjangnya melebihi batas yang ditentukan.

Apabila pengguna memasukkan data melebihi batasannya,makaakanmunculpesankesalahan.Haliniberarti domain integrity yang dibuat telah berjalan dengan baik. 


\section{KESIMPULAN}

Simpulan terhadap sistem basis data manajemen akademik pada platform web pada Sekolah Menengah Atas Muhammadiyah 4 Bandung adalah sistem ini dapat menjawab kebutuhan informasi yang akurat dan cepat dari para stakeholders, seperti guru, wali siswa, kepala sekolah, dan siswa. Bagi para wali siswa secara khusus dapat memantau kegiatan belajar seperti nilai, absensi dan laporan keuangan siswanya. Dengan pendataan yang terkomputerisasi, dapat mencegah terjadinya duplikasi dan inkonsistensi data. Manfaat lainnya dari adanya sistem ini adalah dapat meningkatkan komunikasi antara guru, siswa, dan wali siswa.

Evaluasi entity integrity menghasilkan primary key, di mana primary key tersebut tidak boleh menggunakan "NULL". Selanjutnya evaluasi reference integrity menghasilkan entitas yang telah melalui tahap testing, seperti contoh penambahan nilai pada table Score, akan menambahkan nilai pada table ScoreID.

Hasil testing pada enterprise constraint menunjukkan bahwa constraint dapat digunakan dan sesuai user requirement. Seperti contoh pada UserID, StudentID, TeacherID memiliki constraint 10 karakter saja. Sehingga user tidak dapat menginput lebih dari 10 karakter pada kolom tersebut. Evaluasi tingkat keamanan menunjukkan bahwa semua data yang telah diinput dapat disimpan ke database dan dapat diakses sesuai level user yang menggunakan platform web pada Sekolah Menengah Atas Muhammadiyah 4.

\section{DAFTAR PUSTAKA}

Binusmaya.binus.ac.id

Connolly, T., \& Begg, C. (2015). Database systems. Pearson Education UK.

Damara, Y. R., \& Abadi, A. M. (2017). PENERAPAN QR CODE PADA SISTEM PEMESANAN DI INDUSTRI RETAIL. Jurnal Matematika Vol, 6(6).

Henkie, O. (2008). Teknologi Informasi untuk Perpustakaan: Digital Library Sebagai Solusi Keterbatasan Informasi. Jurnal Piranti Warta, 11(01), Hal-106.

Inayatullah, T. Penerapan open ERP dalam pengembangan modul manajemen kursus: studi kasus lembaga pendidikan dan pelatihan komputer karisma.

Rupp, R. O., \& Russell, J. R. (1994). The golden rules of process redesign. Quality Progress, 27(12), 85.

Setiyawan, A., \& Purnama, B. E. (2013). Pembuatan Sistem Informasi Akademik Berbasis Web Pada Sekolah Menengah Atas Negeri 1 Ngadirojo. IJNS-Indonesian Journal on Networking and Security, 4(3).

Shneiderman, B.\& Plaisant, C. (2010). Designing the user interface : strategies for effective human - computer interaction. (5th Ed.).Cambridge, Massa- chussets: Addison-Wesley.

Susilo, G. (2017). Keamanan basis data pada sistem informasi di era global. Jurnal Transformasi, 12(2).

Wellem, T. (2009). Semantic Web Sebagai Solusi Masalah Dalam E-Tourism Di Indonesia. Jurnal Fakultas Hukum UII 